\title{
The scientific information provided through patents and its limited use in scientific research at universities
}

\author{
Cristiano Gonçalves Pereira ${ }^{1}$, Rodrigo Ribeiro da Silva ${ }^{1}$ and Geciane Silveira Porto ${ }^{2^{*}}$
}

\author{
* Correspondence: geciane@usp.br \\ ¿University of Sao Paulo/ The \\ School of Economics, Business and \\ Accounting of Ribeirao Preto, Av. \\ Bandeirantes, 3900 - Monte Alegre \\ CEP 14049-900, Ribeirão Preto, SP, \\ Brazil \\ Full list of author information is \\ available at the end of the article
}

\begin{abstract}
This study aimed to evaluate the importance of protecting the knowledge generated by the university through patents, and assess the use of information available in patent database as a source of scientific and technological information. To this end, the doctoral theses defended in 2010 to 2012 year at the Basic and Applied Immunology FMRP/USP Post Graduation Program, were evaluated considering patent applications by the authors involved, as well as by other national/international unrelated research groups. The data showed that only $8 \%$ of the thesis (two) had its results added to a patent filing. Moreover, no other student was found to held a patent resulting in other researches, and also, a few supervisors are researchers who held authored/co-authored of patent filling. When we assessed if theses' results and applications had been patented by other groups not related to the thesis group, it was noted that there was no record of patent filling in $46 \%$ of theses, and in this group, it was included researches with strong potential for patentability, but the authors didn't applied for a patent deposit. The remaining 54\%, representing 14 theses, had part or the whole knowledge disclosed in patents documents, five of these were specific about the topic and the results of the thesis, presuming that there was a likely duplicity in the development of the research. We can conclude that the study was once repeated since no searching for information in patents databases were properly performed as reference source in the development phase of their research projects. The results of this research indicates that the use of patents database, as a source of technological information by the universities is an urgent requirement, since represent a rich scientific information bank that should be aggregated with the information available in papers to conduct innovative research.
\end{abstract}

Keywords: Patents; Database; University; Scientific information

\section{Springer}

\section{Background}

According to the World Intellectual Property Organization (WIPO World Intellectual Property Organization 2015) a patent is an exclusive right granted by the State for an invention, which is a product or a process that provides, in general, a new way of doing something, or offers a new technical solution to a problem. In return, the inventors agree to disclose all the technical information about the invention to the public in a patent application.

(c) 2015 Pereira et al.; licensee Springer. This is an Open Access article distributed under the terms of the Creative Commons 
Over twenty years ago, Rapp and Rozek (1990) proposed a link between the protection of intellectual property rights and a country's economic development. They claimed that countries which have a well-structured patent system experience faster economic growth for three reasons: a) Patent rights stimulate economic growth, by enabling these countries to attract a larger influx of inventions as well as greater investment in innovative activities; b) Inadequate protection of industrial property rights is linked to economic underdevelopment; c) Patents and other protective mechanisms increase sales prospects and potential profit. These three types of categories involved in the process of innovation can take on different roles depending on the country, but their presence is essential for economic and technological development. Nowadays it has become clear that the strength and the appropriate type of intellectual property rights enhance innovation and economic growth. In developed countries, where the ability to conduct innovative research exists, the patent protection play more important role in innovation process than in developing countries, which the link innovationeconomic growth is given by minor or incremental inventions based on utility models (Kim et al. 2012). Most countries are massively investing on R\&D activity aiming to reach a stable and sustainable growth based on innovation (Chen et al., 2013).

Universities play a critical role in the development and dissemination of new insights that have innovative and technological potential. The Government is also an important player as, subject to their policies, universities can function in an environment that favors collaboration on innovative projects, integrating technology-based enterprises including the creation of joint ventures with companies (Eun et al. 2006). In addition to encouraging companies to hire graduates or post-graduates to lead R\&D projects (Tödtling et al. 2009), or creating an environment which attracts new technologybased start-ups (Etzkowitz et al. 2005). The research conducted at the university has provide a great improvements such as drug discovery (Toole and Czarnitzki, 2007) and pharmaceutical innovation contributing to lower hospital cost and increased life expectancy (Lichtenberg 2007). Moreover, the U.S. Biotechnology industries have been formed mostly influenced by the university research (Czarnitzki et al., 2011; Zucker and Darby, 1997).

In Brazil, the management of Intellectual Property within Universities has deserved special attention in recent years, particularly after the Law of Innovation. According to Oliveira and Velho (2009), patents resulting from academic research were virtually non-existent before 1980. Up until 1996, the number of applications remained irregular and below fifty per year. Between 1997 and 2001, there was significant growth in the number of approved patents compared to the period directly before it. Meanwhile, it was during 2002-2007 when growth was even more marked, reaching around 350 approved patents resulting from academic research.

Even though the growth in the number of patents for academic research and other sources is encouraging, the situation remains critical. Brazil is in 25th place in terms of the number of patents filed to the WIPO using PCT (Patent Cooperation Treaty) system, behind other emerging economies such as China (3th place), India (17th) and Russia (20st) (WIPO World Intellectual Property Organization 2013). WIPO also record that among the BRICs nations, China went from occupying a marginal position a little over a decade ago to now occupying 3th place in the world rankings. Indeed, they filed 825,136 patents in 2013 , which represents $32.1 \%$ of world total patents, ranking 
the top country of patents fillings in 2013. Brazil has undergone very slow growth recently; with only $1.5 \%$ increase in 2013 compared to previous year, with two universities among top three applicants, State University of Campinas (UNICAMP) and Federal University of Minas Gerais (UFMG).

Despite all efforts, protecting inventions with patents at universities is still a fledgling practice: University researchers predominantly use electronic libraries of scientific articles, failing to take advantage of the wealth of content available in the patent database and to stay updated with regard to the state of technology in their respective research areas. It is beyond debate that a patent document is a formal source of scientific and technological information, as it allows access to technical and legal data of inventions. It is estimated that $70 \%$ of information contained in patent documents are not available in books, technical-scientific articles or any other medium of information (US Patent Trademark Office 1978). For these reasons, this source contain much recent research into the state of technology of many different aspects of human development and it is of great relevance to the development of innovative research.

Using patent databases means that duplication of research into technological innovations can be avoided as well as paving the way to identifying emerging or alternative technologies; providing a platform for commercial applications, showing, for instance, viable alternatives to acquiring technology. It allows the verification of technology availability in Brazil, avoiding litigation, as well as monitoring competing technology (Oliveira et al., 2005).

According to the Austrian Patent Organization (APO), around 30\% of costs could be saved in the area of R\&D in Europe by using information available in patent databases (WIPO and IFIA, 1998). An estimate made by the European Patent Office (EPO and European Patent 2013) showed that approximately US $\$ 20$ billion are wasted in the European Community every year because of duplicate inventions.

Based on the current context of the importance of universities to include the search for patents as a source of scientific and technological knowledge in their research projects, the enquiry arose for the study presented in this paper. Its main aim has been to assess patent applications in relation to new insights unearthed at universities, as contained in doctoral theses. It has tracked the efforts of those on the post-graduate program as well as other national and/or international research groups unconnected to this study. The objective was to monitor if there had been duplicate investments in research and to protect new discoveries via patents. This study examines the practice of intellectual protection within the Immunology program, which includes one of the Post-Graduate programs from Faculty of Medicine of Ribeirao Preto (FMRP/USP), awarded with the highest concept (number 7) on CAPES ranking (Coordination for the Improvement of Higher Education).

\section{Methods}

To perform this study, the Post-Graduate Program in Basic and Applied Immunology at the FMRP/USP, was put under analysis. The program received the maximum rating of 7 in the CAPES ranking evaluation and is regarded as exemplary in its area. The FMRP is one of the three best medical schools in Brazil and a premier medical research center, which is responsible for publishing a great number of articles in international and national journals. This study has focused on examining the content of $\mathrm{PhD}$ theses on patent database, given that a thesis document arise through extensive projects with 
a large number of findings, which should in theory, be unpublished. During the research, we collected all $\mathrm{PhD}$ (digital archive) at the time period of 2010 to 2012. To conduct the research on the patent database, we made use of information contained in the following fields: title, authors, supervisor, keywords, summary and, when necessary, the whole body of the text. One of the largest and most complete patent databases in the world, Thompson Innovation (Thompson Reuters), linked to the Institute of Scientific Information (ISI), was used to carry out the searches. The Thompson Innovation (http:// info.thompsoninnovation.com/) provides access to full-text patents and published applications from the Americas, Europe, and Asia.

Data collection took place in two stages. The first, involved looking for patents taking into account if the authors of the theses, including both the student and the supervisor, had made their patent application in relation to the findings or to the application of the defended thesis subject. This step also consisted of searching for patent applications based on the central topic of the thesis as well as its findings and final applications if were already studied for non-related researchers group (national and international). This step was used to verify if there was already an information available in patent documents about the subject on the thesis study, and to identify those researches which containing new data that could become new filing patents (see Figure 1A). This stage was time-consuming and demanded reading the whole documents to extrapolate the information contained at the abstract, being necessary to collect as much as information to understand the main findings of the theses studies. The diagram at Figure 1 details the stages of research that were undertaken.

In addition, we also evaluated the profile of doctoral students and supervisors in relation to the protection of knowledge produced at the university. We checked the number of patents each of them had and if there were patents directly or indirectly related to the central theme of the thesis, as shown in Figure 1B.

In some cases, in which the national patent document (whole text) was not available to download on the Thompson database, the database of INPI was used. All the data was collected, analyzed and put into a spreadsheet, and the findings were illustrated in a format of graphs.

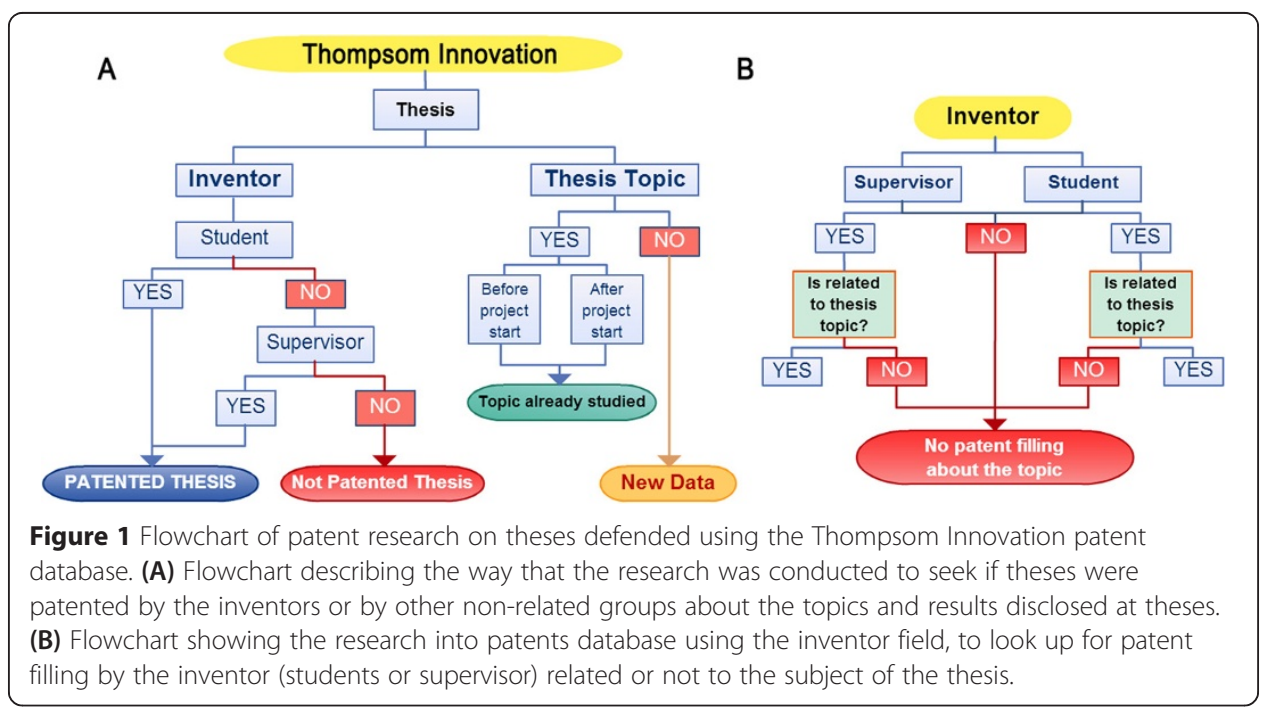




\section{Results}

The evaluation of the occurrence of patent applications in theses, from the Post Graduate Program in Basic and Applied Immunology at the FMRP/USP, discovered a total of 37 theses. Initially, we used the names of the authors who were directly involved in the study (student and supervisor) in Thompson search field "inventor". The results showed that of those students who defended their thesis, only two were listed as inventor in a patent application. Both the doctoral student and supervisor filled these requests as inventors. One of the patent document was filled right after the thesis was defended and include the whole data published in the thesis regarding a new tool to study viral infection. The other document included the main findings regard the thesis document together with some scientific data not cited by the doctoral student. The remaining doctoral students did not have their scientific findings protected by patents (Figure 2). However, of the 35 theses that were not patented, 11 of them belonged to a group of scientific studies whose findings were not patentable or with no commercial applications, not meeting the legal requirements for a patent, such as epidemiological or descriptive studies with no practical application. These studies are important as they deal with a situation or occurrence that has not yet been reported before and, in most cases, they act as useful information for inventions of other researchers. Nevertheless, this study shows little or no inventive activity as well as not having any industrial application. It should be noted that one of the requirements for requesting a patent is industrial application along with an adequate level of description and innovation. Studies that do not meet those criteria, such as work arising from basic research, are not eligible for patent protection. This does not indicate a lack of clarity in the research, only that it does not meet the requirements for a patent. Such studies look to advance understanding in their particular area but lack insight into practical application as they are dealing with basic research.

Once it was noted that just two doctoral student used the results and findings of his/ her thesis to apply for a patent - and being their only two records as co-inventor in

\begin{tabular}{|l|c|c|c|c|}
\hline A & $\begin{array}{c}\text { Not patent } \\
\text { applicable }\end{array}$ & $\begin{array}{c}\text { With } \\
\text { Patents }\end{array}$ & $\begin{array}{c}\text { Without } \\
\text { Patent }\end{array}$ & TOTAL \\
\hline Theses & 11 & 2 & 24 & 37 \\
\hline Doctoral & - & 2 & 35 & 37 \\
\hline Students & - & 8 & 9 & 17 \\
\hline Supervisors & - & &
\end{tabular}

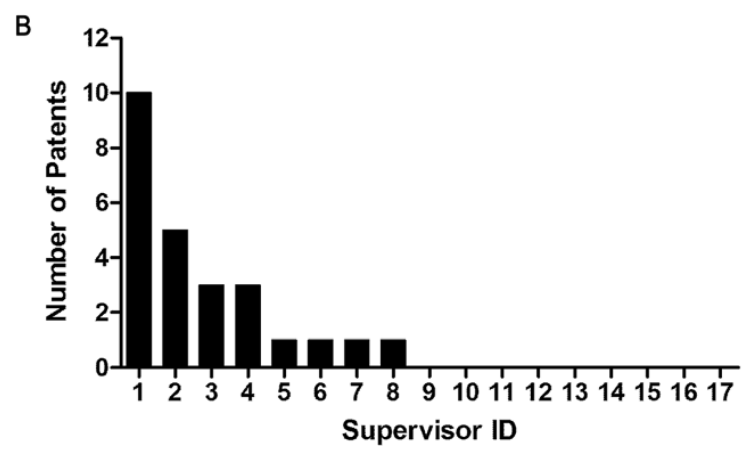

Figure 2 Patents distribution among students and supervisors. A) Table showing the number of patents applied for by post-graduate students and supervisors, as well as applications of theses defended by students in 2010 to 2012. B) The distribution of patent ownership by supervisors represented in the form of table by the number of patents versus supervisors labeled 1 to 17. 
patent documents - the study moved through to the next stage of analysis. The following step was to determine if other students had patent applications on other topics unrelated to their theses. It was found that none of 35 students remaining held any other patent according to Thompson Innovation data bank. This data shows that the protection of findings via patents does not tend to be a common occurrence among post-graduate students. Based on this information, we moved to the next stage: to examine if the lack of patents among students was a trait of the post-graduate environment. In order to do this, we conducted a profile check on the students' supervisors, with respect to patent ownership. The results showed that of the 17 supervisors whose students finished their doctorate in 2010 to 2012, only 8 were reported as inventors in patent documents (Figure 2). In assessing the number of patents that university professors had, it was found that only one supervisor (S.1) stood out for having made 10 patent applications. This indicates that this particular supervisor has a consistent interest in protecting his discoveries at university by patents; representing $43.5 \%$ of the total number of patents in which supervising professors appear as inventors (Figure 2). Furthermore, another two supervisors (S.3 and S.4) registered patents which they co-authored with S.1, also S.5 and S.6 share the same patent registry, both being the only one record of patent ownership by the supervisors. It was noted that only three supervisors have continued studies regarding patents that they have applied for. All patents logged by supervisor 1 deal with the core themes of his/her students' theses, arising from the discovery of a DNA vaccine for tuberculosis. This shows the researcher is interested in producing or continuing to produce new products and applications that enhance their discoveries.

Once completed the analysis of patent applications made by students and supervisors, we focused on examining patent applications for new breakthroughs, results and applications of those theses by other national or international groups who were not directly involved with the group that defended the thesis at the university.

The results showed that there was no record of any patent for new discoveries described in $46 \%$ (10) of the theses defended in 2010-2012, excluding the eleven studies for which patent deposit application was not applicable, described previously. The data shows that the information available in $46 \%$ of theses does not have any description or information available in patent databases. As a result, these studies remain unpublished, which a patent protection could be required. Of those studies with no patent, $80 \%$ had great potential to create an innovative product in the field of biotechnology or to improve an existent one. However, the researchers did not make any applications (Figure 3). Performing an exploratory analysis with these subjects, it was noted that many results derived from the thesis document would be appropriate for a patent filling, among them, we can cite the work of one group of researchers that identified molecules correlated with biomarkers already described for one type of leukemia; another group described a novel strategy for dengue treatment using a drug which has been given little attention up to now; another group discovered a new vaccine strategy using proteins from a parasite that gave an $80 \%$ increase in the survival rate of infected mice, and other new vaccine strategy were described as using tick proteins to prevent infestation in bovines. All of these studies, as well as others not cited here, could have been protected by patents, as they are all innovative and have an industrial use, either in the area of biotechnology or pharmacology. This could have attracted not only the interest of companies to license this patent but also undertake projects together to: (a) hone their development; (b) scale the technology and 


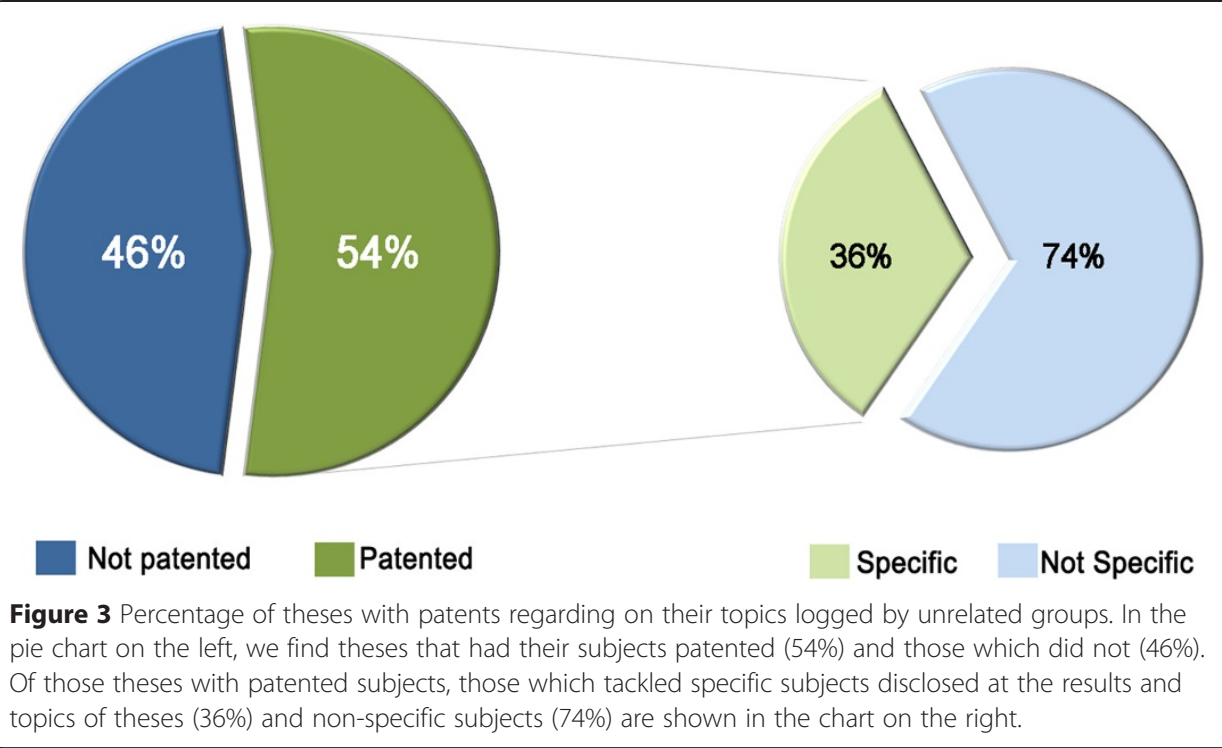

(c) complete its cycle of development to reach the market. Unfortunately, all of these 10 studies have already missed the deadline to apply for a patent in the country. Brazilian law allows for a grace period of 12 months (starting from the thesis defense). However, most countries do not grant such a lengthy time period as the patent application needs to occur at the time of the thesis defense.

On the other hand, we observed that 54\% (14) of the total assessed theses already had part or all of the knowledge related to the study's findings registered in patent applications by other researchers unrelated to the work, preceding the date of the thesis defense. In this case, two situations arose: firstly, we observed that of the 14 theses, $74 \%$ (9) had patents that did not deal with a specific subject from the thesis, but rather the patent document aggregated the knowledge published in the thesis to detail another product related (or not) to the application that the university researchers proposed. Moreover, we observed that in $36 \%$ of theses had previous patents dealing specifically with findings and applications that doctoral student and the researcher published in the thesis. In other words, the central findings of the thesis and its practical applications had already been patented by another group (Figure 3). Regarding this data, it was noted that in the case of theses with a non-specific patent, enough information was already available in patent documents before the defense, and the researchers could take advantage of this and integrate this knowledge to develop more innovative discoveries or even take the research into another direction. The same could have happened to theses that had patents on the subject-matter as well as the specific findings. A lot of knowledge was left to be aggregated during the elaboration of the doctoral student's project, allowing the project to be led forward and finalized, with little or no innovative knowledge.

As an example of non-specific patents regarding the core theme of the theses, we can cite a group of researchers who advocated a method of nasal immunization against a bacterial disease that affects horses and immunosuppressed patients using a specific protein from the pathogen. The same protein was used for the same illness, and there already existed two patents applied for which aggregated diverse and useful data for the 
study. Nevertheless, the thesis distinguished itself for the way in which the protein was transferred to the animal model. In the case of theses with pre-existing applications for specific patents, we identified a group that developed a kind of serological diagnostic test using recombinant viral proteins to identify viral diseases and to immunize mice. There were already five patents applied for on this subject, with the same methodological approach and which used the same peptides as well. Another study used two drugs for the treatment of a viral disease, which also had patents filed using the same methods. These findings show that during the research process, there is still no current practice to verify if the core subject is up to date with the state of technology, in the same way that one usually seeks to demonstrate that the studies are up to date with the current thinking on the subject in hand. As $70 \%$ of our knowledge is found in patent databases, if the choice is made to not check if a potential thesis project lies on the frontier of the state of new technology, it may result in the development of theories that are not as innovative. An important caveat in this analysis is in relation to theses wholly focused on basic research that are not at the frontier of knowledge in whatever way the analysis is conducted.

Regarding the choice of doctoral theses as representatives of new discoveries in the field of science at universities, it was examined whether patent applications protecting part or all of the knowledge contained in theses would invalidate the student's findings in terms of its originality. In that case, we assessed whether the patent applications related to the thesis (Field: patent description) included information which was also described in the full document of the thesis. For this stage, the patent documents as well as the doctoral research were analyzed. We note that, of patents on the topics of the theses, $71.5 \%$ (10) showed that the information generated in the theses it was not a "first" discovery, since a precedence had already been documented by patents, only four studies $(28.5 \%)$ did not fit in this group, such as part of the results of the thesis had been patented, but the research of doctoral student added new discoveries that had not even been mentioned in the patent documents.

\section{Discussion}

The present study has sought to evaluate whether the information available in patent databases is harnessed by universities as a source of scientific and technological information, which, in consequence, could be useful in the preparation of doctoral research projects. We thus assessed whether students and their supervisors actually carried out the filing of patents for doctoral theses defended at the University. The research object were theses defended during 2010 to 2012 at the Post Graduate and Immunology Program - FMRP/ USP. This program presents a significant number of scientific articles with a relevant impact value and as fulfilling the Capes 7 requirements. It was observed that only two of the theses used part or its whole knowledge protected by the patent deposit. In addition, excluding these cases, no other student who completed his doctorate during the analyzed period, had ownership of patent applications. The case scenario, therefore, is that few students develop projects with a view to introducing a new product, process or new technological application. This is due to a lack of interest in researchers to patent a discovery, and ended up failing to disseminate the findings only in scientific journals. 
In terms of doctoral research supervision, little variance is evidenced - few supervisors have patent applications, and those who do so, has an entrepreneurial profile, focusing at the return of the research investment and dedicated to research development. It can be further observed that those who are most eager to patent their discoveries are those which are most focused on research to improve and enhance an already patented product, this then becoming their main line of research, such as supervisor 1 . Yet filing a patent does not inhibit publications as is ever so often erroneously believed by laymen and researchers alike, but sooner guarantees rights: an invention being registered in a patent office means that it can immediately be published (Wolff, 1997).

Contrastingly, to developed countries, which uses the innovation process and technological development as economic strengthening, Brazil lacks a consistent institutional framework, as well as policies, that encourage the protection of intellectual property as a mechanism for economic and social development (Fujino, 2005). Although legal advances have occurred with innovation law, adherence to such regulatory framework and the incorporation of these practices into ICTs (Science and Technology Institutions) remains below the technological capacity of Brazilian ICT's themselves (MCTI and Inovação 2013).

Over the research sample period 2010 to 2012, 10 out of 24 theses did not have information in the patent databank. During this analysis, 11 theses were excluded, as they did not adhere to patenting criteria, which specifies innovation and industrial use. From the total theses analyzed, eight were considered strong in terms of patenting potential: new discoveries with clear industrial applications were evidenced, but there were no strong efforts from researchers to deposit the findings. Therefore, we noticed a gap in the activity of researchers and university policies in encourage the protection of IP, and thus, did not use the benefits of protecting their discoveries in the form of patents. The potential interest of companies to establish cooperative projects and carry out research in order to achieve pre-industrial or industrial status, or even license proprietary technologies, consequently diminishes. Therefore, either for lack of interest, encouragement or information, these researchers gave up a knowledge, which could have economical value in the future. In addition, this value could return to themselves, to university and funding agencies who provided funding (laboratories, supplies, research grants) and research development as a whole. Knowledge under such conditions is less likely to be transformed into wealth.

It is worth noting that only a small percentage of patents actually appear on the market as a new technology and / or product (AUTM US Licensing Activity Survey 2010). Moreover, where the protection of IP remains partial, the possibilities of corporate interest in university knowledge are drastically reduced. Here we can identify the telling necessity for more comprehensive, in-depth studies to get a better handle on the issues facing a researcher's decision not to patent. It is possibly the bureaucratic measures and the time taken to grant a patent that affect a researcher's incentive, or maybe it is the general lack of disclosure on patenting procedures, which cause a researcher's discouragement. The role of TTO (Technological Transfer Offices) is therefore essential to elucidating the matter. The TTOs has joined forces to disseminate the adherence of a patent system, mostly based on workshops, seminar and awards to innovative researchers, focusing on encourage them to start thinking about the intellectual property rights and its benefits. The TTOs has trying to create an environment where 
researchers can and must be motivated with their research environment where procedural conditions for the protection of innovation can and must be easily created.

A doctoral thesis is an original, new and previously un-researched contribution to a field. So far, can all scientific information available be verified and scrutinized? Our research observed that 14 doctoral theses already had patents for the particular research topic advocated by the student. Out of these 14 cases, five had patents that dealt specifically with the student's research. Such a number is alarming, for researchers invest time and resources that can be reduced or eliminated if the available knowledge in the patent database was used. Most importantly, duplicate research and its consequences can be avoided. Oliveira et al. (2005) assert the importance of patent data bases, and that for Brazil, where scientific research is concentrated mainly in academia and government research centers, patent databases are extremely positive not only in terms of the dissemination of patent information for these respective areas, but also for stimulating the literature on patenting technology, for students of undergraduate and postgraduate courses.

\section{Conclusions}

Few researchers and post-graduate students are involved in the application of patents. The idea of patenting knowledge generated at University emerges from an isolated group of academics. There is therefore a real need for much greater awareness in the scientific community regarding the possibility of generating innovative ideas and then protecting them in the form of patents. The patent database needs to be recognized as a highly significant source of scientific information alongside traditional research in scientific articles. In this way, research projects can be undertaken and developed at universities with the aim of producing innovative results with regard to both the subject and the technology. The present research, although exploratory, open up the question not only about developing innovations that may have industrial applications in the future and thereby contributing to the transformation of scientific knowledge in richness by major national universities. The trend of not making use of such a rich and comprehensive source of knowledge as the patent database, which has already been adopted by the best universities in developed countries, may lead to duplicated studies when they could be pushing the boundaries of our understanding or including a broader scope of research.

Researchers have to respect other researcher's decision to not develop a doctoral research thesis that has, as one of its goals, future applications, be it by technology transfer via licensing, or by entrepreneurial activity from a spin-off. Nonetheless, to get a thesis on "unprecedented" status, the current stage of development the knowledge contained in patent documents has to be taken into consideration. To avoid the risk of failure to perform scientific developments that actually contain more significant advances, not to conduct a comprehensive and updated search of the prior art (scientific articles) and the state of the technique (patents) in the initial stage of the research project. 


\section{Competing interests}

We have read and understood BJST policy on declaration of interests and declare that we have no competing interests.

\section{Authors' contributions}

G.S.P. designed the study. G.S.P. and C.G.P developed the concept and designed flowchart for patent analysis. C.G.P. analyzed the data and wrote the paper. C.G.P and R.R.S. performed the analysis and the understanding of thesis when a full text reading was demanded. All authors discussed the results and implications and commented on the manuscript at all stages. All authors read and approved the final manuscript.

\section{Acknowledgements}

This research was supported by FAPESP (São Paulo Research Foundation - 2012/22686-9) who provided the financia support for the research which allowed us to acquire a Thompson Innovation subscription used for patent exploration. We also would like to show our gratitude to Ana Cristine S. Ferreira for assistance with gathering the thesis files used for analysis.

\section{Author details}

'Department of Molecular and Cell Biology, University of Sao Paulo/Faculty of Medicine of Ribeirao Preto, Av. Bandeirantes, 3900 - Monte Alegre CEP 14049-900, Ribeirão Preto, SP, Brazil. ²University of Sao Paulo/ The School of Economics, Business and Accounting of Ribeirao Preto, Av. Bandeirantes, 3900 - Monte Alegre CEP 14049-900, Ribeirão Preto, SP, Brazil.

Received: 2 April 2015 Accepted: 10 April 2015

\section{Published online: 07 May 2015}

\section{References}

AUTM US Licensing Activity Survey (2010) [Association of University Technology Managers (AUTM); 2010, available at http://www.autm.net/FY_2010_Licensing_Survey/9337.htm

Chen C-P, Hu J-L, Yang C-H (2013) Produce patents or journal articles? A cross-country comparison of R\&D productivity change. Scientometrics 94:833-849

Czarnitzki D, Hussinger K, Schneider C (2011) Commercializing academic research: the quality of faculty patenting. Ind Corp Change 20(5):1403-1437

EPO, European Patent Office (2013) http://www.epo.org/searching/essentials/business.html. Accessed 03 Fev 2013

Etzkowitz H, Mello JMC, Almeida M (2005) Towards "meta-innovation" in Brazil: the evolution of the incubator and the emergence of a triple helix. Res Policy 34(4):411-424

Eun J-H, Lee K, Wu G (2006) Explaining the "University-run enterprises" in China: a theoretical framework for universityindustry relationship in developing countries and its application to China. Res Policy 35(9):1329-1346

Fujino A (2005) "Política de Informação e a hélice tripla: reflexões sobre serviços de informação no contexto da cooperação u-e". In: abstracts of VI Encontro Nacional de Ciência da Informação. Salvador- BA, Brazil, 14-17 Jun 2005

Kim YK, Lee K, Park WG, Choo K (2012) Appropriate intellectual property protection and economic growth in countries at different levels of development. Research Policy, 41(2):358-375

Lichtenberg F (2007) The impact of new drugs on US longevity and medical expenditure, 1990-2003: evidence from longitudinal, disease-level data. Am Econ Rev 97(2):438-443

MCTI, Ministério da Ciência e Tecnologia e Inovação (2013) http://www.mcti.gov.br/. Accessed 20 jan 2014

Oliveira RM, Velho LMLS (2009) Patentes acadêmicas no Brasil: uma análise sobre as universidades públicas paulistas e seus inventores. Parc Estrat 14(29): 173-200

Oliveira LG, Suster R, Pinto AC, Ribeiro NM, Silva RB (2005) Informação de patentes: ferramenta indispensável para a pesquisa e o desenvolvimento tecnológico. Quim Nova 28(suplem):S36-\$40

Rapp RT, Rozek RP (1990) Benefits and costs of intellectual property protection in developing countries. J World Trade 24(1):75-102

Tödtling F, Lehner P, Kaufmann A (2009). Do different types of innovation rely on specific kinds of knowledge interactions? Technovation, 29(1):59-71.

Toole A, Czarnitzki D (2007) Biomedical academic entrepreneurship through the SBIR program. J Econ Behav Org 63(4):716-738

US Patent Trademark Office (1978) The uniqueness of patents as a technological resource technology assessment \& forecast, eighth report, US Department of Commerce, Washington, DC. p. 37

WIPO (World Intellectual Property Organization) (2013) World intellectual property indicators., http://www.wipo.int/ ipstats/en/wipi/ 2014 EDITION; Accessed jan 2015

WIPO (World Intellectual Property Organization) (2015) Patents., http://www.wipo.int/patents/en/ Accessed jan 2015

WIPO and IFIA (1998) WIPO-IFIA International Symposium on Inventors and Information Technology, Document prepared by the International Bureau of WIPO, WIPO/IFIA/BUD/98/2

Wolff MT (1997) A pesquisa cientifica e as patentes. Dannemann Siemsen, Rio de janeiro, http://www.egov.ufsc.br/ portal/sites/default/files/anexos/6916-6915-1-PB.html, Accessed 08 jan 2011

Zucker L, Darby M (1997) Individual action and the demand for institutions star scientists and institutional transformation. Am Behav Sci 40(4):502-513 